\title{
Control Algorithm Selection Technique for Vehicle Robotic Transmission in the Urban Cycle
}

\author{
Evgeniy Sarach ${ }^{1,}$, Alexander Tsipilev ${ }^{1}$, and Igor Smirnov ${ }^{2}$ \\ ${ }^{1}$ Bauman Moscow State Technical University, Russia \\ ${ }^{2}$ Moscow Polytechnic University, Russia
}

\begin{abstract}
Environmental pollution is one of the most crucial problems in modern world. The toughening of emission standards for toxic fumes, which appear due to the combustion of fossil fuels in internal combustion engines, forces manufacturers to reduce fuel consumption, for example, via more rational use of the internal combustion engine capabilities. This paper is devoted to developing a control algorithm selection technique for economy class passenger car robotic transmission in the conditions of an urban cycle, using Lada Vesta SW Cross as a research subject. At the beginning of the paper, vehicle movement imitational mathematical model implementation, which was developed using LMS Imagine.Lab Amesim program complex. is shown. Also the main assumptions and parameters of engines, cooling systems, transmissions and chassis are given. Then imitational mathematical model verification results, which were processed by comparing movement computer simulation results with the vehicle passport data, are shown. Imitational mathematical model demonstrates the car behavior adequately and very precisely, which means it can be used for vehicle fuel efficiency research. In the main part of the paper, vehicle movement research is conducted in case of three different versions of the internal combustion engine (which has 1,4-, 1,6- and 1,8-liters volume) used in an urban cycle INRETS urbanfluide2. It is clearly shown that the lowest consumption is achieved by reducing the acceleration and braking dynamics via "early" gear shifting, and the crankshaft rotation speed at the corresponding moment of the shift has to be selected for each gear separately. Based on the research results, a switching algorithm and its selection technique, which takes the throttle valve opening degree and the type of the internal combustion engine external speed characteristic into consideration, are presented. In conclusion, this paper presents the results of vehicle movement imitational mathematical modeling in the urban cycle with a modified robotic transmission control algorithm. It is clear that this algorithm can reduce fuel consumption in the urban cycle by $12-20 \%$, depending on the engine volume.
\end{abstract}

\section{Introduction}

Complex technical devices engineering is impossible without a comprehensive research of both their individual parts and the entire mechanism as a whole. Imitational mathematical

*Corresponding author: sarach@yandex.ru 
modeling is most often used for this purpose. It implies creating a real object mathematical display, using algebraic and differential equations. This method can be used to simulate real mechanical system conduct in a way similar to how it would work in reality [1]. Imitational mathematical model (IMM) creation requires the need to make certain assumptions, since the formation of a real system accurate mathematical representation is extremely difficult, impossible, or just pointless.

Nowadays there are several software packages, which can simplify an IMM creation process. Such packages are very convenient to use due to possibilities to both vary IMM main parameters and carry out computational experiment. For example, LMS Imagine.Lab Amesim package is designed to simulate mechatronic systems' dynamics [2]. Its main advantage is the ability to use already made blocks that simulate the conduct of a node with certain predetermined assumptions. Using the various libraries of the package, it is possible to simulate complex mechanical systems with varying degrees of detailing.

In this paper movement IMM of an economy class passenger car, which is similar to the Lada Vesta SW Cross with a robotic gearbox in terms of parameters, was created in LMS Imagine.Lab Amesim, including the internal combustion engine (ICE) and transmission models. Also, movement dynamics research under typical loading conditions was conducted.

\section{Car imitational mathematical model implementation}

Passenger car imitational mathematical model was created using the IFP Drive library in order to conduct its movement dynamics research. Weight and size parameters, the ICE external speed characteristic and its construction parameters, transmission type and gear ratios were used as the initial data. The general scheme of imitational mathematical model is shown in Fig.1.

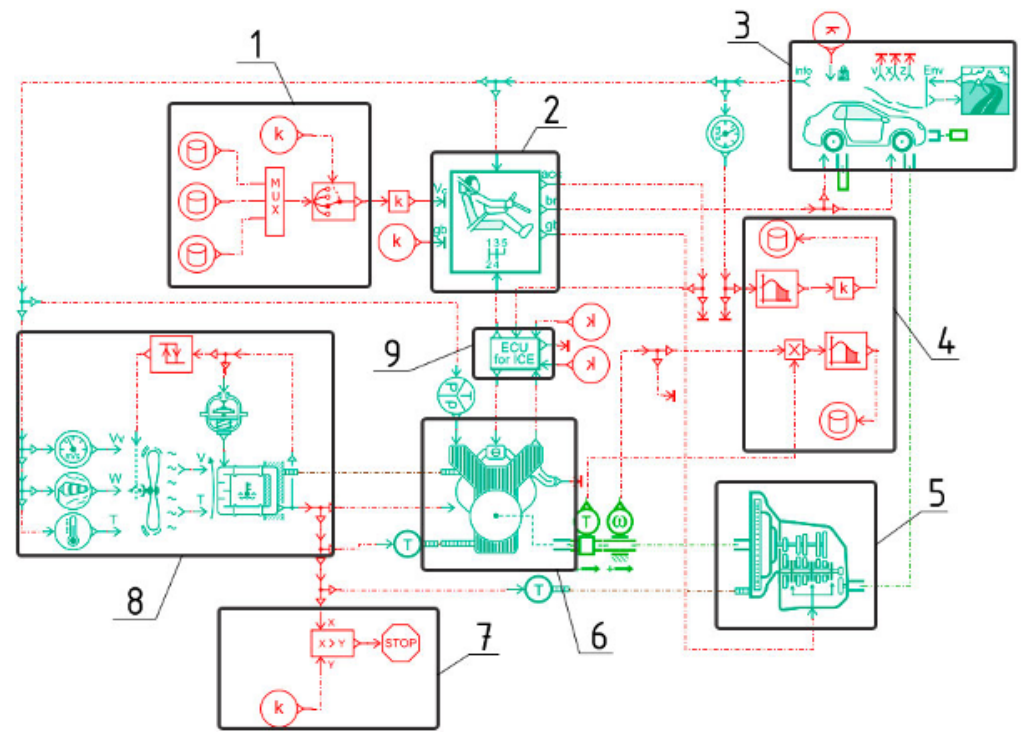

Fig. 1. Imitational mathematical model implementation:

1 - car movement input data block 2 - driver's actions simulation block; 3 - chassis and the environment (including the support base) interaction simulation block; 4 - car movement average speed and average power calculation block; 5 - robotic gearbox operation simulation block; 6 - ICE operation simulation block; 7 - simulation stopping block (in case of coolant temperature is exceeded); 8 - engine cooling system simulation block; 9 - engine control block (engine calculator) 


\section{Internal combustion engine model}

For ICE operation simulation their parameters (Table 1 and Fig.2 [3-5]) were used as the initial data. The environmental parameters were set in advance (Table 2).

Table 1. VAZ engines parameters

\begin{tabular}{|c|c|c|c|}
\hline Parameter & \multicolumn{3}{|c|}{ Value } \\
\hline Engine code & 11194 & 21129 & 21179 \\
\hline Engine weight, $\mathrm{kg}$ & 100 & 108 & 109 \\
\hline Coolant total mass, $\mathrm{kg}$ & \multicolumn{3}{|c|}{8,7} \\
\hline Fuel used & \multicolumn{3}{|c|}{ petrol } \\
\hline Cylinder configuration & \multicolumn{3}{|c|}{ inline } \\
\hline Number of cylinders & \multicolumn{3}{|c|}{4} \\
\hline Ignition method & \multicolumn{3}{|c|}{ spark } \\
\hline Turbocharge & \multicolumn{3}{|c|}{ none } \\
\hline Working volume, $\mathrm{sm}^{3}$ & 1390 & 1596 & 1774 \\
\hline Compression ratio & 10,8 & 10,5 & 10,3 \\
\hline Piston stroke, $\mathrm{mm}$ & \multicolumn{2}{|c|}{75,6} & 84,0 \\
\hline Piston diameter, $\mathrm{mm}$ & 76,5 & \multicolumn{2}{|c|}{82,0} \\
\hline Efficiency ratio & & & 0,34 \\
\hline Fuel combustion specific heat, $\mathrm{kJ} / \mathrm{kg}$ & \multicolumn{3}{|c|}{42000} \\
\hline Stoichiometric ratio & \multicolumn{3}{|c|}{14,7} \\
\hline
\end{tabular}

Table 2. Environment parameters

\begin{tabular}{|l|c|}
\hline Parameter & Value \\
\hline Environment (air) temperature, ${ }^{\circ} \mathrm{C}$ & 20 \\
\hline Atmospheric pressure, bar & 1,013 \\
\hline Atmospheric air density, $\mathrm{kg} / \mathrm{m}^{3}$ & 1,185 \\
\hline
\end{tabular}

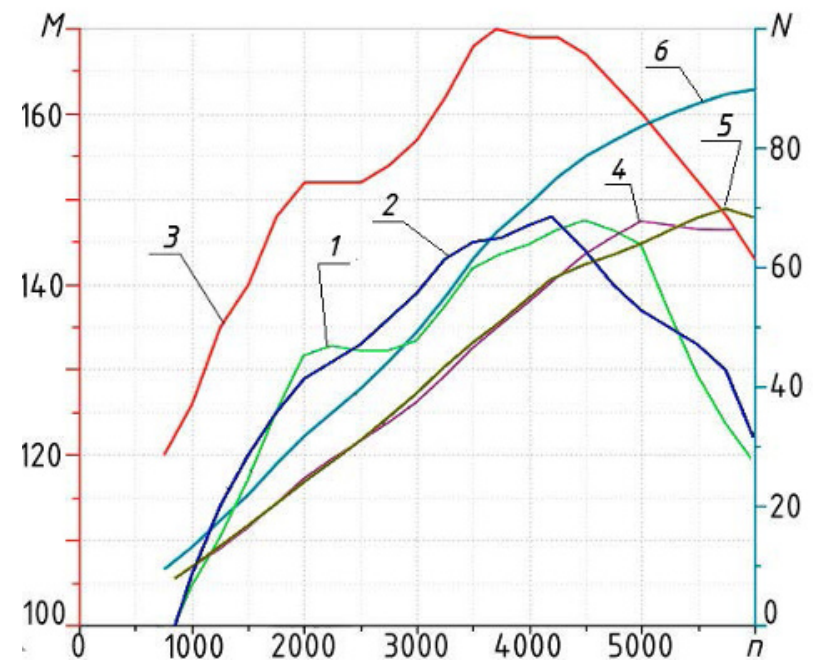

Fig. 2. VAZ ICE external characteristics:

1, 2, 3 -VAZ 11194, VAZ 21129, VAZ 21179 ICE torque respectively;

4, 5, 6-VAZ 11194, VAZ 21129, VAZ 21179 ICE developed power respectively

$n$ - crankshaft rotation frequency, $\mathrm{rpm} ; M$ - torque, $\mathrm{N} \cdot \mathrm{m}$;

$N$ - power, kW 
Mechanical and gas losses, three-dimensional charts of specific fuel consumption and other parameters are calculated in the ICE model. They are used to simulate the operation of a cooling system (cooling system parameters are presented in Table 3) that consists of a radiator, thermostat, fan, and fan control unit. The engine operation input data is the information which comes from the engine control unit. Also, the parameters calculated during the cooling system unit operation, and environmental parameters such as air temperature, density and pressure are taken into consideration.

Table 3. Cooling system parameters

\begin{tabular}{|l|c|}
\hline Parameter & Value \\
\hline Small circuit coolant mass, $\mathrm{kg}$ & 2,5 \\
\hline Coolant total mass, $\mathrm{kg}$ & 8,7 \\
\hline Small circuit heat exchange area, $\mathrm{m}^{2}$ & 0,8 \\
\hline Liquid - cylinder block heat transfer ratio, $\mathrm{W} / \mathrm{m}^{2} \cdot \mathrm{K}$ & 100 \\
\hline Cylinder block - air heat transfer ratio, $\mathrm{W} / \mathrm{m}^{2} \cdot \mathrm{K}$ & 10 \\
\hline Radiator heat exchange area, $\mathrm{m}^{2}$ & 0,5 \\
\hline Initial coolant temperature, ${ }^{\circ} \mathrm{C}$ & 20 \\
\hline Thermostat opening start temperature, ${ }^{\circ} \mathrm{C}$ & 85 \\
\hline Thermostat full opening temperature, ${ }^{\circ} \mathrm{C}$ & 95 \\
\hline Fan switch-on temperature, ${ }^{\circ} \mathrm{C}$ & 105 \\
\hline Fan switch-off temperature, ${ }^{\circ} \mathrm{C}$ & 99 \\
\hline Air flow rate with the fan running, $\mathrm{m} / \mathrm{s}$ & 10 \\
\hline
\end{tabular}

\section{Robotic gearbox model}

A robotic gearbox with one clutch is used in the model. It structurally corresponds to the mechanical gearbox installed in "Priora" and "Vesta" cars. Its gear ratios are presented in Table 4.

The input data for the operation of the model are: ICE crankshaft rotation frequency, oil temperature in the transmission and expected gear number are used as the input data for the model operation. The output parameter is the torque, which is applied to the chassis driving axle.

Table 4. Transmission parameters

\begin{tabular}{|l|c|}
\hline Parameters & Value \\
\hline Gear change minimum time, $s$ & 1,6 \\
\hline Average efficiency ratio & 0,96 \\
\hline Gear ratios & 3,$636 ; 1,95 ; 1,357 ; 0,941 ; 0,784 ;-3,5$ \\
\hline Main pair gear ratio & 3,938 \\
\hline
\end{tabular}

\section{Chassis model}

The IFP Drive library block DRIVEH01 is used as the chassis model. Its parameters are presented in Table 5. The environmental parameters, the torque at the transmission output, information about the braking torque change are used as the input data. A set of quantities, which are necessary for the adequate operation of the rest of the machine general model components, are set as the output data. 
Table 5. Chassis parameters

\begin{tabular}{|l|c|}
\hline Parameter & Value \\
\hline Vehicle weight, $\mathrm{kg}$ & 1300 \\
\hline $\begin{array}{l}\text { Mass distribution along the axes: } \\
\text { front axle } \\
\text { rear axle }\end{array}$ & 59 \\
& 41 \\
\hline Drag ratio & 0,38 \\
\hline Drag area, $\mathrm{m}^{2}$ & 2,735 \\
\hline Adhesion ratio & 0,8 \\
\hline Movement resistance ratio & 0,03 \\
\hline Tire parameters & $195 / 55 \mathrm{R} 16$ \\
\hline Maximum braking torque on the front/rear axle $\mathrm{N} \cdot \mathrm{m}$ & $2000 / 1000$ \\
\hline
\end{tabular}

\section{Driver model}

The driver model used in the car movement general model is a block, which simulates the driver's function for cars with a robotic transmission. The current and desired vehicle speed are used as an input data, and the accelerator pedal position and brake pedal position are set as the output data. The unit also transmits information about the robotic transmission selected operating mode to the corresponding unit. In fact, the model implements a PID controller.

The calculated parameters are used in engine and transmission models, as well as in the control action formation on chassis brakes.

\section{Imitational mathematical model verification}

In order to assess the accuracy and adequacy of the imitational mathematical model, its verification was carried out by comparing the results of mathematical simulation and experimental data. The passport data of the kilometer fuel consumption during a drive in the suburban cycle EPA Highway Fuel Economy Cycle (HWFET), used in the fuel efficiency study [6], are set as the experimental data. The cycle chart is shown in Fig. 3.

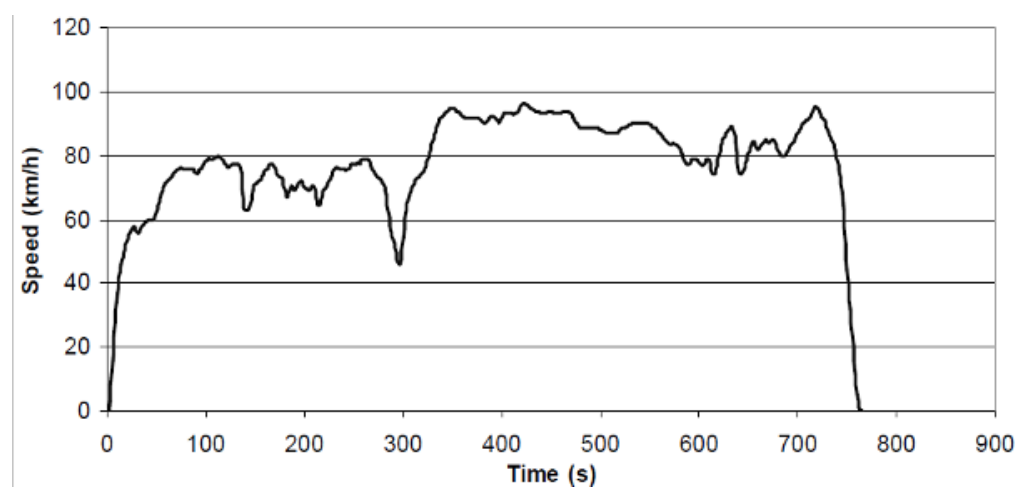

Fig. 3. HWFET cycle chart

Simulation results in comparison to the passport data are represented in Table 6. 
Table 6. Verification results

\begin{tabular}{|l|c|c|c|}
\hline Engine code & 11194 & 21129 & 21179 \\
\hline Consumed fuel mass, g & 660,17 & 693,50 & 743,84 \\
\hline Traversed path, m & \multicolumn{3}{|c|}{16500} \\
\hline Fuel consumption, 1/ 100 km: & & & \\
According to passport & 5,30 & 5,30 & 6,00 \\
Based on the simulation results & 5,33 & 5,60 & 6,01 \\
In the urban cycle, according to passport (for & - & 10,1 & 9,7 \\
reference) & $0,6 \%$ & $5,7 \%$ & $0,2 \%$ \\
\hline Error
\end{tabular}

The verification results indicate that the created vehicle imitational mathematical model is adequate and accurate.

\section{Fuel efficiency research in urban cycle}

The fuel efficiency research is carried out in a driving mode corresponding to the urban cycle INRETS urbanfluide2 [6]. Its chart is shown in Fig. 4.

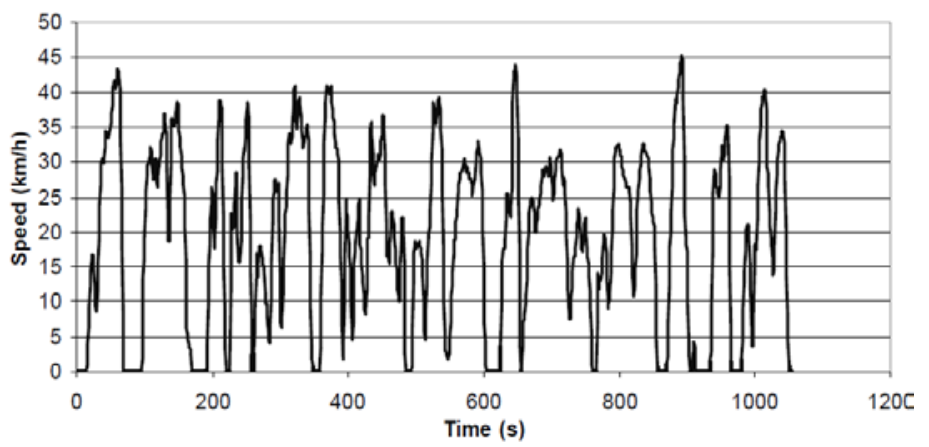

Fig. 4. INRETS urbanfluide2 cycle chart

During the simulation process, the fuel consumption is the controlled parameter, and the gear shift mode (the gearbox input shaft rotation frequency at the moment of the gear shift) is the variable one. The initial switching mode corresponds to the following algorithm:

- shifting the gear to an increased one - at a speed of $3000 \mathrm{rpm}$;

- shifting the gear to a lower one - at a speed of $1500 \mathrm{rpm}$.

The simulation is carried out according to the initial gear shifting algorithm. The simulation results are presented in Table 7 .

Table 7. Simulation results

\begin{tabular}{|l|c|c|c|}
\hline Engine code & 11194 & 21129 & 21179 \\
\hline Simulation time, $\mathrm{s}$ & \multicolumn{3}{|c|}{1053} \\
\hline Traversed path, m & 5640 & 5637 & 5634 \\
\hline Average speed, kmph & 19,3 & 19,3 & 19,3 \\
\hline Consumed fuel mass, $\mathrm{g}$ & 482,2 & 526,3 & 561,6 \\
\hline Fuel consumption, 1/ 100 km: & 11,4 & 12,4 & 13,3 \\
\hline
\end{tabular}

The specific flow rate decreases as it approaches the maximum torque point, and then increases again. Thus, it is advisable to shift the gear at the maximum torque point only when a throttle is completely open. Then the switching function can be represented using the equation: 


$$
E_{u}=n+\Delta n \cdot a c c,
$$

where $\mathrm{Eu}$ - crankshaft rotation frequency at the moment of a gear shift to an increased gear, rpm;

$\mathrm{n}$ - some fixed crankshaft rotation frequency, rpm;

$\Delta \mathrm{n}$ - variable crankshaft rotation frequency, rpm;

acc - throttle valve opening stage ( 0 - closed, 1 - fully open).

The algorithm point is to choose such values of $n$ and $\Delta n$, so the fuel consumption in each gear is the least. Since the speed reduction usually occurs when the pedal is not pressed, downshifting should be done at low crankshaft rotation frequencies.

Table 8 shows the gear ratios and the values of the gearbox input shaft rotation frequencies for upshifts, and in table 9 - for downshifts.

Table 8. Upshift parameters

\begin{tabular}{|l|l|l|l|l|}
\hline Gear number & $1-2$ & $2-3$ & $3-4$ & $4-5$ \\
\hline Gear ratio & 1,865 & 1,437 & 1,442 & 1,200 \\
\hline Input shaft rotation frequency, rpm & 2280 & 2960 & 2950 & 3540 \\
\hline
\end{tabular}

Table 9. Downshift parameters

\begin{tabular}{|l|c|c|c|c|c|}
\hline Gear number & $5-4$ & $4-3$ & $3-2$ & $2-1$ & $1-$ neutral \\
\hline Input shaft rotation frequency, rpm & 1300 & 1200 & 1200 & 1050 & 600 \\
\hline
\end{tabular}

\section{Modeling the movement of a car with VAZ 11194 engine}

The initial simulation results are presented in Fig. 5-7.

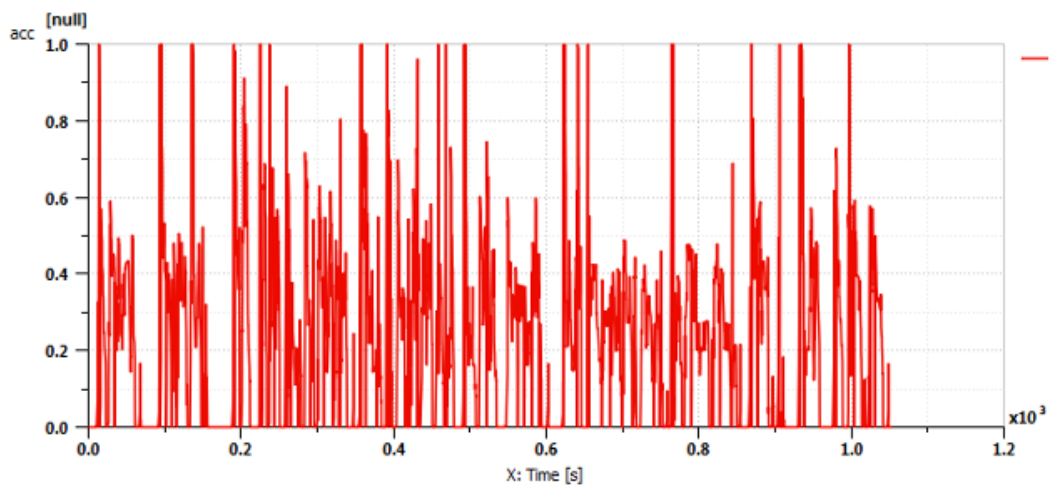

Fig. 5. Accelerator pedal position:

acc - accelerator pedal relative position; $\mathrm{X}$ - simulation time, $\mathrm{s}$

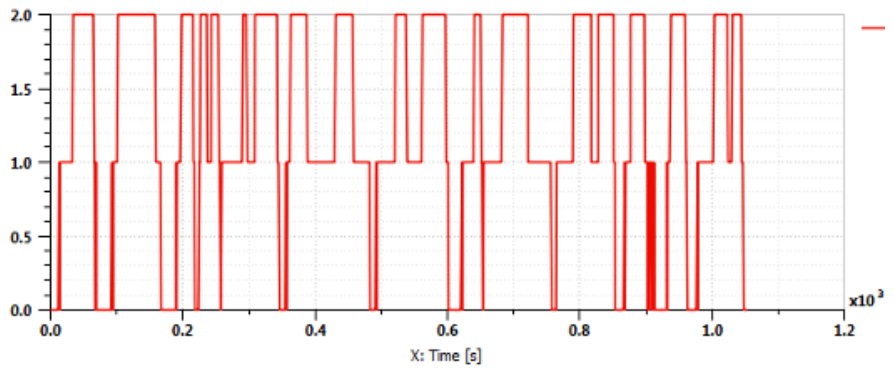

Fig. 6. Gearbox operating modes: $\mathrm{Y}$-axis - gear number; $\mathrm{X}$ - simulation time 


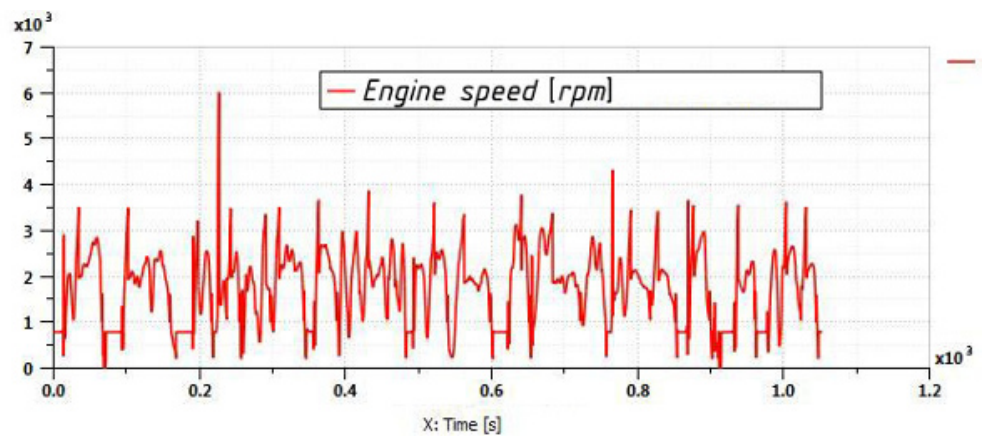

Fig. 7. Engine crankshaft rotation frequency

Fig. 5 resumes that most of the time the pedal is pressed down for no more than $40 \%$. In this case, as it can be seen from Fig. 6, there is no shift above second gear. The crankshaft rotation frequency change record is shown in Fig. 7.

Fig. 7 resumes that the rotation frequency does not exceed $4000 \mathrm{rpm}$, except for two peaks. Then the shifting moment can be selected in the range from 2000 to $3000 \mathrm{rpm}$ with the accelerator pedal position from 0.3 to 0.4 :

$$
4500=n+\Delta n \cdot 1,3000=n+\Delta n \cdot 0,4,2000=n+\Delta n \cdot 0,3 .
$$

Such record gives the initial data for two transmission operation modes:

$$
\begin{aligned}
& \left\{\begin{array} { l } 
{ 4 5 0 0 = n + \Delta n \cdot 1 , } \\
{ 3 0 0 0 = n + \Delta n \cdot 0 , 4 , }
\end{array} \Rightarrow \left\{\begin{array}{l}
n=2000, \\
\Delta n=2500,
\end{array}(\text { Mode 1) }\right.\right. \\
& \left\{\begin{array} { l } 
{ 4 5 0 0 = n + \Delta n \cdot 1 , } \\
{ 2 0 0 0 = n + \Delta n \cdot 0 , 3 , }
\end{array} \Rightarrow \left\{\begin{array}{l}
n=930, \\
\Delta n=3570 .
\end{array}(\text { Mode 2) }\right.\right.
\end{aligned}
$$

Simulation results for both modes are shown in Table 10.

Table 10. Simulation results

\begin{tabular}{|l|c|c|}
\hline Parameter & Mode 1 & Mode 2 \\
\hline Consumed fuel mass, g & 458,4 & 445,2 \\
\hline Fuel consumption, 1/ 100 km: & & \\
Before the algorithm change & 11,40 & 11,40 \\
After the algorithm change & 10,80 & 10,52 \\
\hline Consumption relative reduction, \% & 5,26 & 7,71 \\
\hline
\end{tabular}

Mode 2 is more rational in terms of reducing fuel consumption. Fig. 8 resumes that the crankshaft rotation frequency is higher at lower gears than at higher ones. However, to reduce fuel consumption, low rotation frequency value is advisable.

Thus, the shift time points for the first three gears should be adjusted so that the crankshaft rotation frequency does not exceed $2500 \mathrm{rpm}$. A number of mathematical experiments have shown that the most economical mode is achieved with the parameters shown in Table 11, which also shows the final fuel consumption and the consumption relative reduction. 
Table 11. Simulation results

\begin{tabular}{|c|c|c|c|c|}
\hline Parameter & \multicolumn{4}{|c|}{ Value } \\
\hline Gear shift & $1-2$ & $2-3$ & $3-4$ & $4-5$ \\
\hline Constant rotation frequency value $n, \mathrm{rpm}$ & 1000 & \multicolumn{3}{|c|}{1035} \\
\hline Variable rotation frequency value $\Delta n, \mathrm{rpm}$ & 2500 & & & 3250 \\
\hline Consumed fuel mass, $\mathrm{g}$ & \multicolumn{4}{|c|}{429,0} \\
\hline $\begin{array}{c}\text { Fuel consumption, } 1 / 100 \mathrm{~km} \text { : } \\
\text { Before the algorithm change } \\
\text { After the algorithm change }\end{array}$ & \multicolumn{4}{|c|}{$\begin{array}{l}11,40 \\
10,14\end{array}$} \\
\hline Consumption relative reduction, $\%$ & \multicolumn{4}{|c|}{11,10} \\
\hline
\end{tabular}

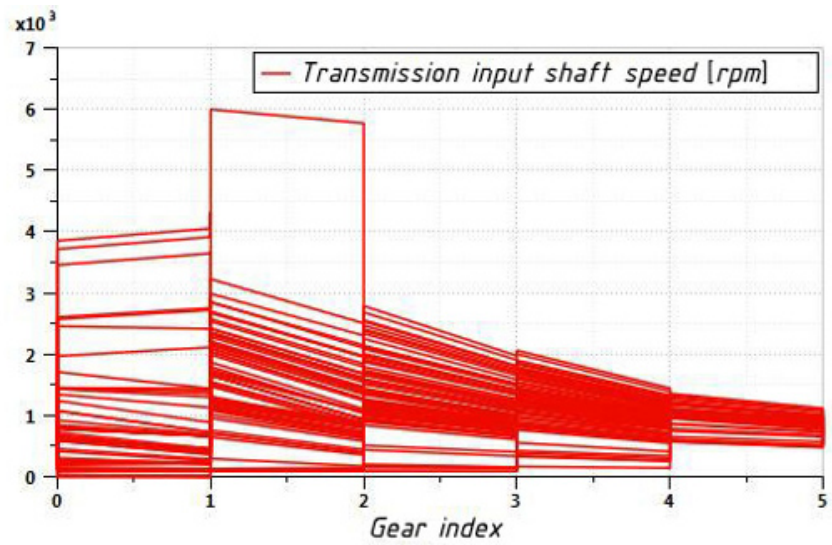

Fig. 8. Gearbox input shaft rotation frequency in different gears

\section{Modeling the movement of a car with VAZ 21129 engine}

For the VAZ 21129 ICE, the maximum torque is achieved at a crankshaft rotation frequency of $4200 \mathrm{rpm}$ (Fig. 2, line 2). Considering the movement of the machine in a way, similar to VAZ 11194 case, the following can be noted: most of the time the pedal is not pressed down for more than $50 \%$ (Fig. 9), there is no shift above the second gear (Fig. 10), the crankshaft rotation frequency does not exceed $3500 \mathrm{rpm}$ (Fig. 11).

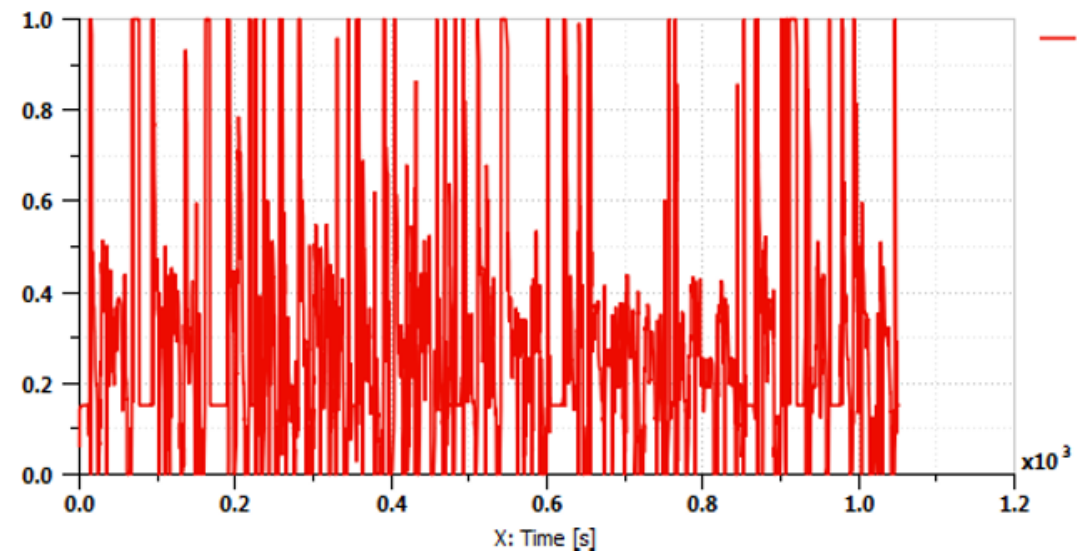

Fig. 9. Accelerator pedal position: acc - accelerator pedal relative position; $X$ - simulation time, $s$ 


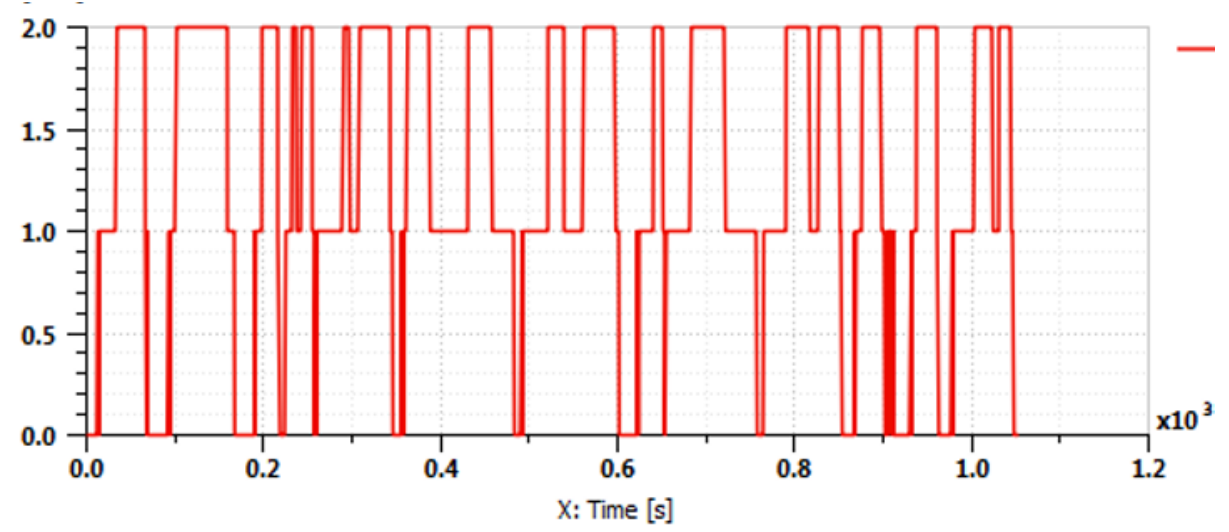

Fig. 10. Gearbox operating modes: $\mathrm{Y}$-axis - gear number; $\mathrm{X}$ - simulation time

The crankshaft rotation frequency change record is shown in Fig. 11.

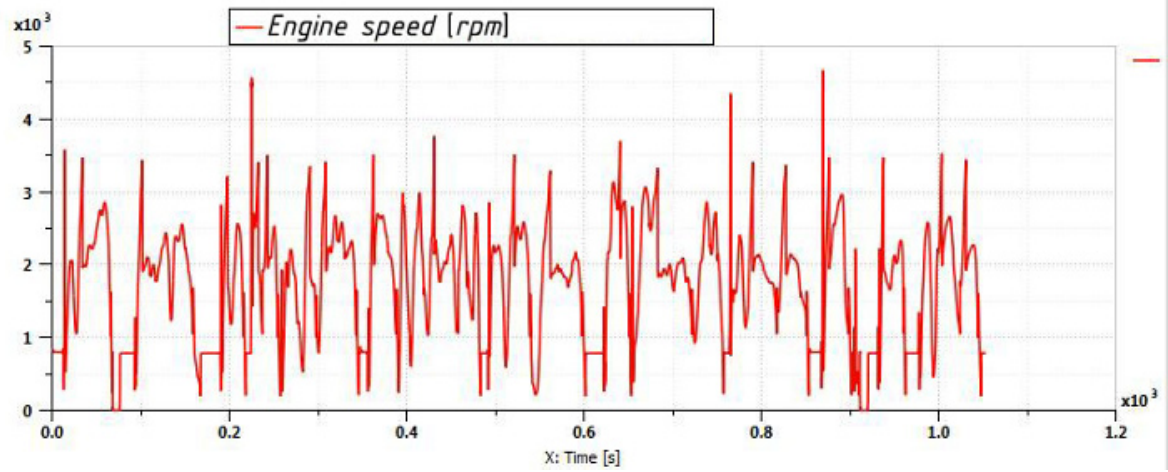

Fig. 11. Engine crankshaft rotation frequency

The mathematical function can be presented as the set of the following equations:

$$
4200=n+\Delta n \cdot 1,3000=n+\Delta n \cdot 0,4,1500=n+\Delta n \cdot 0,2 .
$$

Then:

$$
\begin{aligned}
& \left\{\begin{array} { l } 
{ 4 2 0 0 = n + \Delta n \cdot 1 , } \\
{ 3 0 0 0 = n + \Delta n \cdot 0 , 4 , }
\end{array} \Rightarrow \left\{\begin{array}{l}
n=2200, \\
\Delta n=2000,
\end{array}\right.\right. \text { (Mode 1) } \\
& \left\{\begin{array} { l } 
{ 4 2 0 0 = n + \Delta n \cdot 1 , } \\
{ 1 5 0 0 = n + \Delta n \cdot 0 , 2 , }
\end{array} \Rightarrow \left\{\begin{array}{l}
n=825, \\
\Delta n=3375 .
\end{array}\right.\right. \text { (Mode 2) }
\end{aligned}
$$

The simulations results for these two modes are presented in Table 12.

Mode 2 is more rational in terms of reducing fuel consumption. By operating in a similar manner to the previous case, an additional consumption reduction can be achieved by earlier downshifting in lower gears. The results are shown in Table 13.

Table 12. Simulation results

\begin{tabular}{|l|c|c|}
\hline Parameter & Mode 1 & Mode 2 \\
\hline Consumed fuel mass, g & 501,4 & 484,1 \\
\hline Fuel consumption, 1/ 100 km: & & \\
Before the algorithm change & 12,40 & 12,40 \\
After the algorithm change & 11,82 & 11,40 \\
\hline Consumption relative reduction, \% & 4,68 & 8,06 \\
\hline
\end{tabular}


Table 13. Simulation results

\begin{tabular}{|c|c|c|c|c|}
\hline Parameter & \multicolumn{4}{|c|}{ Value } \\
\hline Gear shift & $1-2$ & $2-3$ & $3-4$ & $4-5$ \\
\hline Constant rotation frequency value $n, \mathrm{rpm}$ & \multicolumn{4}{|c|}{835} \\
\hline Variable rotation frequency value $\Delta n, \mathrm{rpm}$ & 2500 & & & 3375 \\
\hline Consumed fuel mass, $\mathrm{g}$ & \multicolumn{4}{|c|}{467,2} \\
\hline $\begin{array}{l}\text { Fuel consumption, } 1 / 100 \mathrm{~km} \text { : } \\
\text { Before the algorithm change } \\
\text { After the algorithm change }\end{array}$ & \multicolumn{4}{|c|}{$\begin{array}{l}12,40 \\
1100\end{array}$} \\
\hline Consumption relative reduction, $\%$ & \multicolumn{4}{|c|}{11,29} \\
\hline
\end{tabular}

\section{Modeling the movement of a car with VAZ 21179 engine}

For the VAZ 21179 ICE the maximum torque is achieved at a crankshaft rotation frequency of $3750 \mathrm{rpm}$ (Fig. 2, line 3). Thus, the switching algorithm can be described using the following equation (1)

$$
E_{u}=2500+1250 a c c .
$$

The simulation results are presented in Table 14. According to the simulation results analysis, fuel consumption in this switching mode is decreased by $15.48 \%$. Fig. 12 resumes the accelerator pedal position record during the vehicle movement. Most of the time the pedal is pressed down for no more than $40 \%$. In this case (Fig. 13), there is no shift above the third gear.

Table 14. Simulation results

\begin{tabular}{|l|c|}
\hline Parameter & Value \\
\hline Consumed fuel mass, g & 477,3 \\
\hline Fuel consumption, 1/ 100 km: & 13,30 \\
Before the algorithm change & 11,24 \\
After the algorithm change & 15,48 \\
\hline Consumption relative reduction, \% & \\
\hline
\end{tabular}

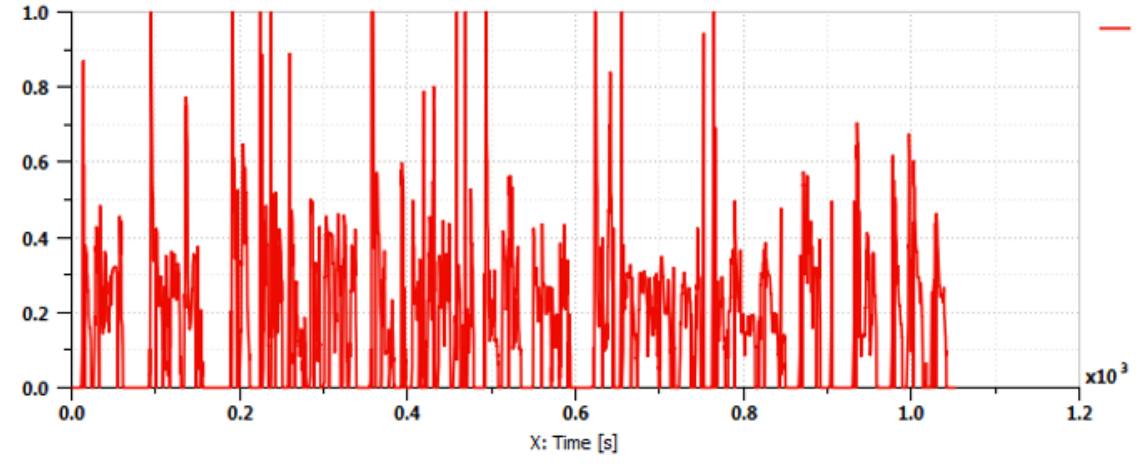

Fig. 12. Accelerator pedal position: (acc - accelerator pedal relative position); $X$ - simulation time, $s$ 


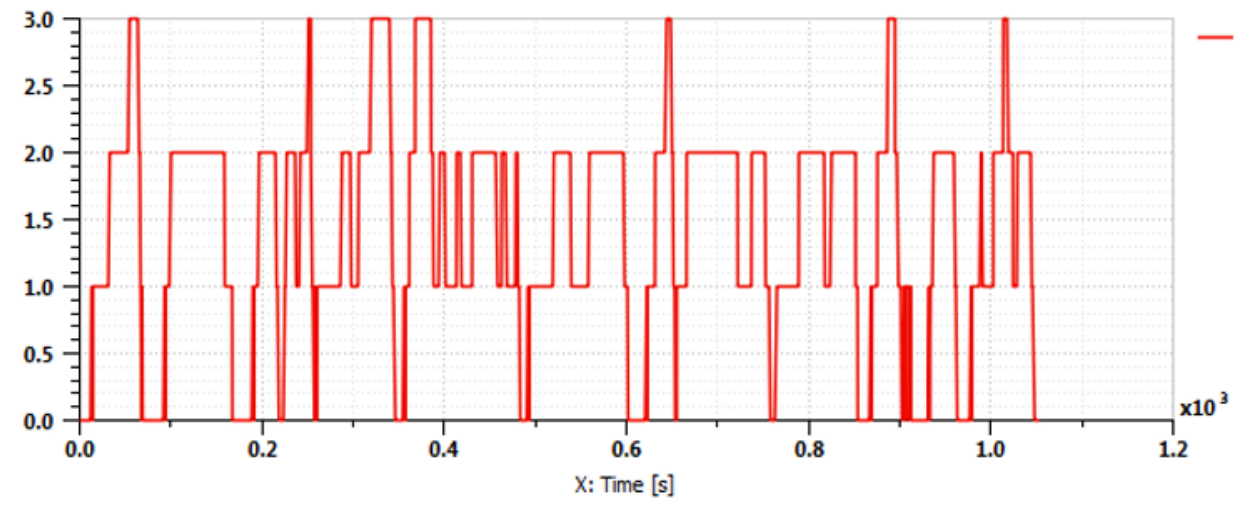

Fig. 13. Gearbox operating modes: $Y$-axis - gear number; $X$ - simulation time

The crankshaft rotation frequency change record is shown in Fig. 15.

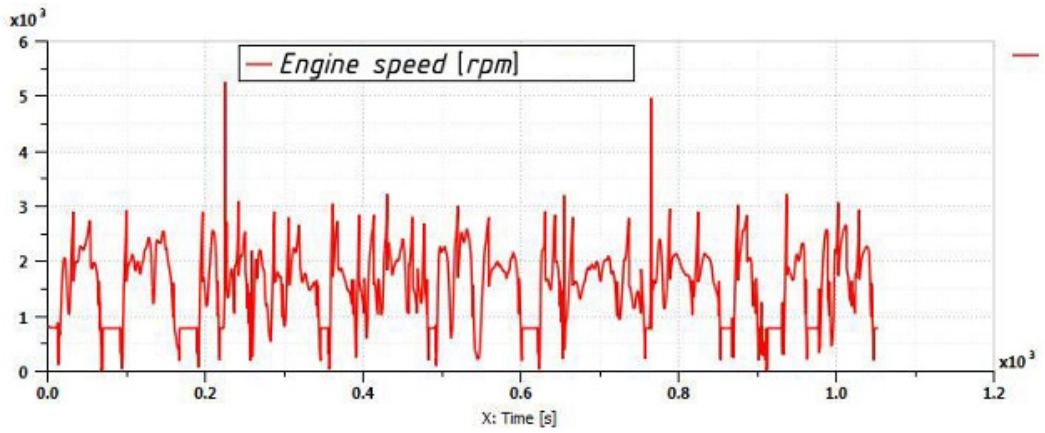

Fig. 14. Engine crankshaft rotation frequency

Fig. 14 resumes that the rotation frequency does not exceed $3000 \mathrm{rpm}$, except for a few peaks. At the same time the shifting moment must be in the range from 1500 to $3000 \mathrm{rpm}$ with the accelerator pedal position from 0.2 to 0.4 . Thus, equation (1) would be as follows:

$$
3750=n+\Delta n \cdot 1,3000=n+\Delta n \cdot 0,4,1500=n+\Delta n \cdot 0,2 .
$$

The resulting equation system can be solved by using combinations of two expressions out of three. Then the following options are obtained:

$$
\begin{aligned}
& \left\{\begin{array} { l } 
{ 3 7 5 0 = n + \Delta n \cdot 1 , } \\
{ 3 0 0 0 = n + \Delta n \cdot 0 , 4 , }
\end{array} \Rightarrow \left\{\begin{array}{l}
n=2500, \\
\Delta n=1250,
\end{array}\right.\right. \text { (Mode 1) } \\
& \left\{\begin{array} { l } 
{ 3 7 5 0 = n + \Delta n \cdot 1 , } \\
{ 1 5 0 0 = n + \Delta n \cdot 0 , 2 , }
\end{array} \Rightarrow \left\{\begin{array}{l}
n=940, \\
\Delta n=2810 .
\end{array}\right.\right. \text { (Mode 2) }
\end{aligned}
$$

The first mode corresponds to the one, that was already considered. Thus, only the second mode should be considered accordingly. Table 15 shows the first and second switching modes simulation results.

Table 15. Simulation results

\begin{tabular}{|l|c|c|}
\hline Parameter & Mode 1 & Mode 2 \\
\hline Consumed fuel mass, g & 477,3 & 430,6 \\
\hline Fuel consumption, 1/ 100 km: & & \\
Before the algorithm change & 13,30 & 13,30 \\
After the algorithm change & 11,24 & 10,13 \\
\hline Consumption relative reduction, \% & 15,48 & 23,80 \\
\hline
\end{tabular}


According to the simulation results (Table 16), Mode 2 is more rational in terms of reducing fuel consumption. By adjusting the shift point in lower gears, it is possible to achieve an even greater fuel consumption reduction.

Table 16. Simulation results

\begin{tabular}{|c|c|c|c|c|}
\hline Parameter & \multicolumn{4}{|c|}{ Value } \\
\hline Gear shift & $1-2$ & $2-3$ & $3-4$ & $4-5$ \\
\hline Constant rotation frequency value $n, \mathrm{rpm}$ & \multicolumn{4}{|c|}{940} \\
\hline Variable rotation frequency value $\Delta n, \mathrm{rpm}$ & 2500 & 2200 & & \\
\hline Consumed fuel mass, $\mathrm{g}$ & \multicolumn{4}{|c|}{429,5} \\
\hline $\begin{array}{l}\text { Fuel consumption, } 1 / 100 \mathrm{~km} \text { : } \\
\text { Before the algorithm change } \\
\text { After the algorithm change }\end{array}$ & \multicolumn{4}{|c|}{$\begin{array}{l}13,30 \\
10,10\end{array}$} \\
\hline Consumption relative reduction, $\%$ & \multicolumn{4}{|c|}{24,06} \\
\hline
\end{tabular}

\section{Conclusions}

The fuel consumption determination error does not exceed $5.7 \%$. Thus, the performed computational experiments demonstrate the adequacy and accuracy of the created imitational mathematical model.

Fuel consumption in the urban cycle depends on the gearshift algorithm. The minimum fuel consumption in the urban cycle for a car with a VAZ 11194 ICE is $10.141 / 100 \mathrm{~km}$; with VAZ 21129 ICE it is $11.01 / 100 \mathrm{~km}$; with VAZ 21179 ICE it is $10.11 / 100 \mathrm{~km}$.

The most economical driving mode is achieved via "early" gear shifting, when the crankshaft rotation frequency does not exceed $2000-2500 \mathrm{rpm}$.

The VAZ 21179 ICE shows the best fuel consumption results, comparable to the VAZ 11179 engine, due to the maximum torque achieved at lower crankshaft rotations frequency. At the same time, the VAZ 11194 ICE also demonstrates a low fuel consumption value, since the working volume of this engine is the smallest. Also its fuel consumption at rotation frequencies, close to idle, is less as well compared to the other engines.

\section{References}

1 Imitational modeling // Wikipedia. Update date: 02.07.2018. Access mode: https://ru.wikipedia.org/?oldid=93700067.

2 LMS Imagine.Lab Amesim // Siemens. Access mode: https://www.plm.automation.siemens.com/ru/products/lms/imagine-lab/amesim/.

3 VAZ 21179 engine: technical characteristics and features // VestaXray. Access mode: http://vestaxray.ru/model/lada-vesta/dvigatel-vaz-21179-tehnicheskieharakteristiki.html.

4 VAZ 11194 engine: technical characteristics and features // Engineer's workshop. Access mode: http://www.motors-vaz.ru/vaz11194.html.

5 VAZ 21129 engine - characteristics and reviews// Lada-online. Access mode: https://xn-80aal0a.xn--80asehdb/car-description/reviews-tests/lada-vesta-reviews-tests/1036harakteristiki-i-otzyvy-o-dvigatele-vaz-21129-lada-vesta-i-xray.html.

6 T.J. Barlow, S. Latham, I.S. McCrae and P.G. Boulter. A reference book of driving cycles for use in the measurement of road vehicle emissions. TRL Limited (2009). 